\title{
2. SYNOPSIS
}

\begin{tabular}{|l|l|l|}
\hline $\begin{array}{l}\text { Name of Company: } \\
\text { I.R.I.S. } \\
\text { 6 place des Pléiades } \\
\text { 92415 Courbevoie - France }\end{array}$ & $\begin{array}{l}\text { Individual Study Table } \\
\text { Referring to Part } \\
\text { of the Dossier }\end{array}$ & (For National Authority Use only) \\
\hline $\begin{array}{l}\text { Name of Finished Product: } \\
\text { VASTAREL } 35 \mathrm{mg}-\end{array}$ & Volume: & \\
\hline $\begin{array}{l}\text { Name of Active Ingredient: } \\
\text { Trimetazidine MR 35mg }\end{array}$ & Page: & \\
\hline
\end{tabular}

Title of study:

Study of the effect of trimetazidine MR $35 \mathrm{mg}$ ( $2 \mathrm{tabs} /$ day) on the emergence of choroidal neovascularisation in age-related macular degeneration. A multicenter, randomised, double-blind, placebo-controlled, phase III study in 1100 patients treated for 3 to 5 years - France DMLA 2 - Protocol No.: MC3 - 06790 - 001

\section{Main Coordinator :}

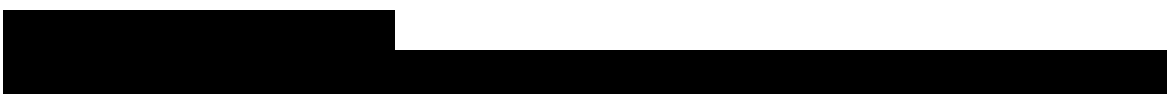

Coordinator in Belgium:

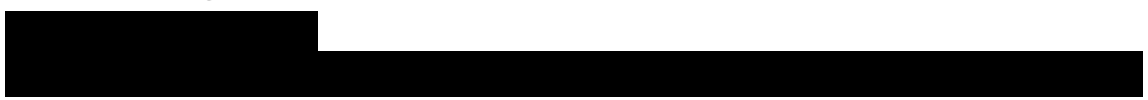

Coordinator in Spain:

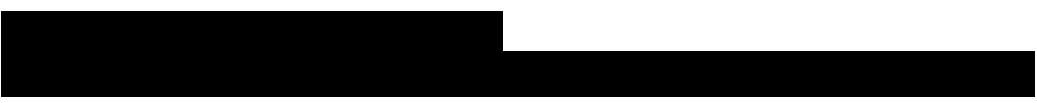

Angiography Reading Committee

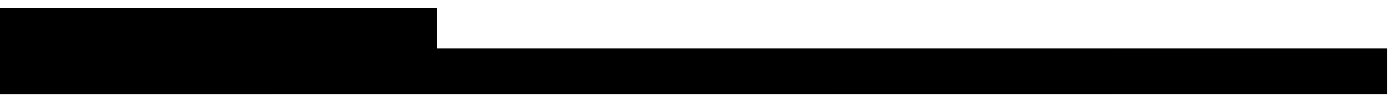

Monitoring Committee

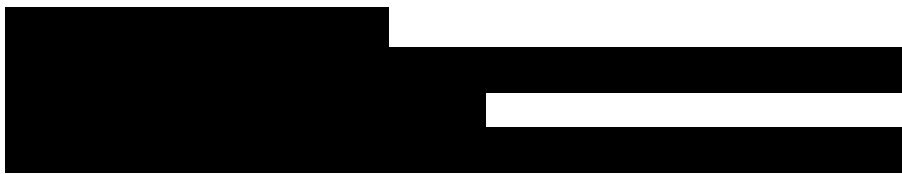

\section{Study centres:}

417 centres of ophthalmology in 3 countries: 398 in France, 13 in Spain and 6 in Belgium.

324 active centres: 307 in France (1375 patients selected, 991 included), 11 in Spain (107 patients selected, 74 included) and 6 in Belgium (136 patients selected, 127 included)

\section{Publication (reference):}

Studied period:

Initiation date: 19 March 1999

Completion date: 31 October 2005

\section{Objectives:}

The primary objective was $t$ o study, using fluorescein retinal angiography, the effect of trimetazidine MR $35 \mathrm{mg}$ on the emergence of, and time to emergence of, choroidal neovascularisation vessels in the studied eye, compared to baseline.

The secondary objectives were $t$ o determine by using fluorescein retinal angiography the effect of trimetazidine MR $35 \mathrm{mg}$ on the occurrence of, and time to occurrence of, atrophy exceeding 1/3 of the papillary diameter in the studied eye, the evol ution of the drusen and pigment epithelium lesions, the characterisation of the choroidal neovascularisation, and to evaluate the clinical acceptability of trimetazidine MR $35 \mathrm{mg}$. 


\begin{tabular}{|l|l|l|}
\hline $\begin{array}{l}\text { Name of Company: } \\
\text { I.R.I.S. } \\
\text { 6 place des Pléiades } \\
\text { 92415 Courbevoie - France }\end{array}$ & $\begin{array}{l}\text { Individual Study Table } \\
\text { Referring to Part } \\
\text { of the Dossier }\end{array}$ & (For National Authority Use only) \\
\hline $\begin{array}{l}\text { Name of Finished Product: } \\
\text { VASTAREL@ } 35 \mathrm{mg} \text { - }\end{array}$ & Volume: & \\
\hline $\begin{array}{l}\text { Name of Active Ingredient: } \\
\text { Trimetazidine MR 35mg }\end{array}$ & Page: & \\
\hline
\end{tabular}

\section{Methodology:}

This multicenter, international, phase III study with randomised, double-blind, comparative design was implemented in 2 parallel groups, one receiving trimetazidine MR $35 \mathrm{mg}$ and the other placebo (2 tabs/day). 1100 patients, aged 55 to 83 years, of Caucasian origin, and presenting with AMD characterised by neovascularisation lesions in one eye (the first eye) and serous drusen or lesions of the pigment epithelium in the contralateral eye (which was the only eye studied) were to be included.

After a treatment-free screening period of, at most, 3 months, during which a fluorescein retinal angiography was conducted and validated by the Reading Committee for enabling the patient's inclusion, the study treatment was allocated by randomisation with minimisation on 3 criteria: age, gender and type of AMD lesions in the studied eye.

The patients included in the study were to be followed up and treated for 3 to 5 years (i.e. until the end of the third year of follow-up for the last patient included) or until emergence of neovascularisation in the studied eye (validated by the Reading Committee). Follow-up visits were scheduled every 6 months and a contact by phone in the 2 months preceding each visit. Every year or in the event of exacerbation of the symptoms or in case of withdrawal, a fluorescein retinal angiography had to be conducted as per the angiography protocol defined and forwarded to the Reading Committee.

\section{Number of participants:}

Planned: 1100 (550 by treatment group)

Enrolled: 1618 - Selected: 1607

Included: 1192 (TMZ 35mg: 594; placebo: 598)

Safety Set: 1189 (TMZ 35mg: 593; placebo: 596)

FAS: 1086 (TMZ 35mg: 546; placebo: 540)

\section{Diagnosis and main criteria for inclusion:}

\section{Selection criteria:}

- male or female of Caucasian origin, aged 55 to 83 years (amendment No. 2),

- presenting with ocular media that are sufficiently clear to ena ble implementation of good quality angiography, and AMD characterized by:

- for the first eye, neovascularisation lesions preferably discovered less than 12 months previously

- $\quad$ and, in the contralateral eye, which was the eye under study:

- $\quad$ either isolated serous drusen or drusen associated with other types of drusen or lesions of the pigment epithelium,

- or isolated lesions of the pigment epithelium

(for patients already having undergone laser phototherapy or radiotherapy on the first eye, the previous angiographic images were to be forwarded to the angiography Reading Committee in order to enable identification of the previous neovascularisation),

- after having been informed, to give informed consent in writing.

Angiographic criteria for patient inclusion: (double reading by Reading Committee using a predefined grading system)

- a good quality angiography with the required number of images,

- unilateral neovascularisation lesion of the first eye: neovascularisation vessels defined and/or occult or any other neovascular form as per the grading system defined,

- and on the eye under study:

- $\quad$ at least 5 isolated serous drusen $(\varnothing>63 \mu)$,

- $\quad$ or at least 5 serous drusen $(\varnothing>63 \mu)$ associated with other types of drusen or lesions of the PE,

- $\quad$ or isolated lesions of the PE. 


\begin{tabular}{|l|l|l|}
\hline $\begin{array}{l}\text { Name of Company: } \\
\text { I.R.I.S. } \\
\text { 6 place des Pléiades } \\
\text { 92415 Courbevoie - France }\end{array}$ & $\begin{array}{l}\text { Individual Study Table } \\
\text { Referring to Part } \\
\text { of the Dossier }\end{array}$ & (For National Authority Use only) \\
\hline $\begin{array}{l}\text { Name of Finished Product: } \\
\text { VASTAREL@ } 35 \mathrm{mg} \text { - }\end{array}$ & Volume: & \\
\hline $\begin{array}{l}\text { Name of Active Ingredient: } \\
\text { Trimetazidine MR 35mg }\end{array}$ & Page: & \\
\hline
\end{tabular}

Diagnosis and main criteria for inclusion: (cont'd)

Non selection criteria:

- Ophthalmologic criteria:

- Allergic reaction during a previous fluorescein angiography;

- Form of AMD not complying with the inclusion criteria, i.e. a study eye presenting with:

- choroidal neovascularisation irrespective of type,

- chorioretinal atrophy (of a dimension 1/3 of the papillary diameter),

- detachment of the pigment epithelium (DPE),

- $\quad$ subretinal material deposits suggesting the presence of pseudo-vitelliform dystrophy;

- $\quad$ Dense cataract, corneal or vitreous opacity, etc.;

- Inadequate pupil dilatation interfering with angiography;

- Myopia of the eye under study greater than -6 diopters (measured with far-sight correction);

- $\quad$ Diabetic retinopathy (irrespective of stage);

- Optical neuropathy: recognized glaucomatous neuropathy, toxic or inflammatory neuropathy or other macular disease (clarified by amendment No. 2).

- Treatment-related criteria

- $\quad$ Patient already treated with t rimetazidine $20 \mathrm{mg}$ (Vastarel $20 \mathrm{mg}$ ) and whose treatment cannot be discontinued (a wash-out period of 15 days was required to enable patient inclusion in the study);

- $\quad$ Patient receiving long-term treatment with potential retinal toxicity (clarified by amendment No. 2):

- synthetic antimalarial,

- tiliquinol, tilbroquinol (Intetrix $\left.{ }^{\circledR}\right)$,

- $\quad$ thioridazine $\left(\right.$ Melleril ${ }^{\circledR}$ ) at a dose superior to $800 \mathrm{mg} /$ day,

- tamoxifen (Nolvadex ${ }^{\circledR}$ ),

- $\quad$ indometacin $\left(\right.$ Indocid $\left.^{\circledR}\right)$ at a dose superior to $150 \mathrm{mg} /$ day.

- $\quad$ Patient having undergone laser macular treatment on the eye under study.

- General criteria

- $\quad$ Patient presenting with a serious life-threatening disease or disease liable to compromise follow-up to the end of the study;

- $\quad$ Patient unlikely to be able to complete the study (moving house scheduled, etc.);

- $\quad$ Serious heart, kidney or liver failure, serious respiratory insufficiency;

- $\quad$ Patient presenting with vitamin A deficiency (malabsorption, etc.);

- $\quad$ Patient unable to attend the various controls scheduled for the study;

- $\quad$ Patient taking part in another study or having taken part in a clinical study in the month preceding the study;

- Patient not having signed the informed consent form.

\section{Study drug:}

Trimetazidine MR $35 \mathrm{mg}, 2$ tablets daily

Batch No. (see appendix 16.1.6.1)

\section{Reference product:}

Placebo, 2 tablets daily

Batch No. (see appendix 16.1.6.1)

\section{Duration of treatment:}

Screening period: 3 months at most

Active treatment period: 3 to 5 years (i.e. 3 years after the last patient inclusion) 


\begin{tabular}{|l|l|l|}
\hline $\begin{array}{l}\text { Name of Company: } \\
\text { I.R.I.S. } \\
\text { 6 place des Pléiades } \\
\text { 92415 Courbevoie - France }\end{array}$ & $\begin{array}{l}\text { Individual Study Table } \\
\text { Referring to Part } \\
\text { of the Dossier }\end{array}$ & (For National Authority Use only) \\
\hline $\begin{array}{l}\text { Name of Finished Product: } \\
\text { VASTAREL® } 35 \mathrm{mg} \text { - }\end{array}$ & Volume: & \\
\hline $\begin{array}{l}\text { Name of Active Ingredient: } \\
\text { Trimetazidine MR 35mg }\end{array}$ & Page: & \\
\hline
\end{tabular}

\section{Criteria for evaluation:}

\section{Primary efficacy criterion:}

Incidence and time to occurrence of choroidal neovascularisation in the studied eye.

\section{Secondary efficacy criteria:}

- Occurrence and time to occurrence of an atrophy above $1 / 3$ of the papillary diameter.

- Evolution of the serous drusen:

- Changes between baseline and last fo llow-up in ap pearance of the serous drusen (highest grade present within the external circle and grade most frequently observed inside the external circle).

- Changes between baseline and last follow-up in the maximum size of the serous drusen in the eye as a whole.

- Changes between baseline and follow-up in the mean over all subfiel ds of the number, size a nd density of serous drusen.

- Evolution of the area covered by the serous drusen in their main location.

- Evolution of the area of hypo- and hyperpigmentation.

\section{Safety assessment criteria:}

- Adverse events.

- Evolution of the optimal acuity with correction far and near in both eyes.

- Evolution of the intraocular pressure in both eyes.

- Occurrence of cataract or cataract extraction during the study period.

\section{Statistical methods:}

Analysis was a final analysis. Objectives were to de monstrate a diffe rence between trimetazidine MR $35 \mathrm{mg}$ and placebo. Tests were bilateral, the type I error $\alpha$ was set at $5 \%$ for all analyses.

Primary efficacy criterion: time to occurrence of choroidal neovascularisation was analysed on the FAS, as main analysis, and the Per Protocol Set 1 Year (PPS 1 Year), as sensitivity analysis.

The following tests were performed in both sets:

- as main analysis: a Cox semi-parametric regression model without adjustment for covariates;

- as sensitivity analyses: a Cox reg ression with adjustment on age classes and non-parametric comparisons using the non-stratified log-rank test and the log-rank test stratified on age classes.

Secondary efficacy criterion: were analysed on the FAS, as main analysis, and the Per Protocol Set 3 Years (PPS 3 Years) as sensitivity analysis.

Qualitative changes (occurrence, emergence) were analysed using a Chi-square test on the patients at risk and quantitative changes using the t-test as main analysis and the Wilcoxon's rank sum test as sensitivity analysis.

For time to occurrence of atrophy, the same tests as for the primary criterion were used 


\begin{tabular}{|c|c|c|c|c|c|}
\hline $\begin{array}{l}\text { Name of Company: } \\
\text { I.R.I.S. } \\
6 \text { place des Pléiades } \\
92415 \text { Courbevoie - France }\end{array}$ & \multicolumn{3}{|c|}{$\begin{array}{l}\text { Individual Study Table } \\
\text { Referring to Part } \\
\text { of the Dossier }\end{array}$} & \multicolumn{2}{|c|}{ (For National Authority Use only) } \\
\hline $\begin{array}{l}\text { Name of Finished Product: } \\
\text { VASTAREL }{ }^{\circledR} 35 \text { mg - }\end{array}$ & \multicolumn{3}{|l|}{ Volume: } & & \\
\hline $\begin{array}{l}\text { Name of Active Ingredient: } \\
\text { Trimetazidine MR } 35 \mathrm{mg} \\
\end{array}$ & \multicolumn{3}{|l|}{ Page: } & & \\
\hline \multicolumn{6}{|l|}{ SUMMARY - CONCLUSIONS } \\
\hline \multicolumn{6}{|l|}{ STUDY POPULATION AND OUTCOME } \\
\hline \multicolumn{6}{|l|}{ Disposition of patients and analysis sets } \\
\hline & \multicolumn{2}{|c|}{ Trimetazidine MR 35mg } & \multicolumn{2}{|r|}{ Placebo } & Whole population \\
\hline Enrolled & & & & & 1618 \\
\hline Selected & & & & & 1607 \\
\hline Included (randomised) & 594 & & & 598 & 1192 \\
\hline Lost to follow-up & $\mathbf{0}$ & & & $\mathbf{0}$ & $\mathbf{0}$ \\
\hline Withdrawn & 135 & & & 164 & 299 \\
\hline Due to adverse event & 59 & & & 68 & 127 \\
\hline Due to lack of efficacy & 2 & & & 1 & 3 \\
\hline Due to non medical reason & 74 & & & 95 & 169 \\
\hline Completed with neovascularisation & 181 & & & 178 & 359 \\
\hline Completed without neovascularisation & 278 & & & 256 & 534 \\
\hline Safety Set & $593(99$ & $\%)$ & 596 & $6(99.7 \%)$ & $1189(99.7 \%)$ \\
\hline Full Analysis Set & $546(91$ & $\%)$ & 540 & $0(90.3 \%)$ & $1086(91.1 \%)$ \\
\hline PPS 1 Year & $429(72$ & $\%)$ & 418 & $8(69.9 \%)$ & $847(71.1 \%)$ \\
\hline PPS 3 Years & $268(45$ & $\%)$ & 246 & $6(41.1 \%)$ & $514(43.1 \%)$ \\
\hline \multicolumn{6}{|l|}{$\%: \%$ of Included Set } \\
\hline \multicolumn{6}{|l|}{ Main baseline characteristics in the FAS } \\
\hline & & \multicolumn{2}{|c|}{$\begin{array}{l}\text { TMZ MR } 35 \mathrm{mg} \\
\quad(N=546)\end{array}$} & $\begin{array}{c}\text { Placebo } \\
(N=540)\end{array}$ & $\begin{array}{c}\text { All FAS } \\
(N=1086)\end{array}$ \\
\hline Age (years) & $\begin{array}{c}\mathrm{N} \\
\text { Mean } \pm \mathrm{SD} \\
\text { Median } \\
\text { Min ; Max }\end{array}$ & \multicolumn{2}{|c|}{$\begin{array}{c}546 \\
73.35 \pm 5.66 \\
74 \\
54 ; 90\end{array}$} & $\begin{array}{c}540 \\
73.73 \pm 5.59 \\
74 \\
53 ; 84 \\
\end{array}$ & $\begin{array}{c}1086 \\
73.54 \pm 5.63 \\
74 \\
53 ; 90 \\
\end{array}$ \\
\hline \multirow[t]{2}{*}{$\leq 70$ years } & $\mathrm{n}(\%)$ & \multicolumn{2}{|c|}{$147(26.9 \%)$} & $144(26.7 \%)$ & $291(26.8 \%)$ \\
\hline & $\mathrm{n}(\%)$ & \multicolumn{2}{|c|}{$399(73.1 \%)$} & $396(73.3 \%)$ & $795(73.2 \%)$ \\
\hline \multirow{2}{*}{$\begin{array}{l}\leq 75 \text { years } \\
>75 \text { years }\end{array}$} & $\mathrm{n}(\%)$ & \multicolumn{2}{|c|}{$333(61.0 \%)$} & $304(56.3 \%)$ & $637(58.7 \%)$ \\
\hline & $\mathrm{n}(\%)$ & \multicolumn{2}{|c|}{$213(39.0 \%)$} & $236(43.7 \%)$ & $449(41.3 \%)$ \\
\hline Sex & $\begin{array}{c}\mathrm{N} \\
\mathrm{n}(\%)\end{array}$ & \multicolumn{2}{|c|}{$\begin{array}{c}546 \\
210(38.5 \%)\end{array}$} & $\begin{array}{c}540 \\
206(381 \%)\end{array}$ & $\begin{array}{c}1086 \\
416(383 \%)\end{array}$ \\
\hline Female & $\mathrm{n}(\%)$ & $336(61$ & & $334(61.9 \%)$ & $670(61.7 \%)$ \\
\hline $\begin{array}{c}\text { Family history of AMD } \\
\text { Yes }\end{array}$ & $\begin{array}{c}\mathrm{N} \\
\mathrm{n}(\%)\end{array}$ & $\begin{aligned} 546 \\
64(11 .\end{aligned}$ & & $\begin{array}{c}540 \\
63(11.7 \%)\end{array}$ & $\begin{array}{c}1086 \\
127(11.7 \%)\end{array}$ \\
\hline $\begin{array}{l}\text { Time since onset of neovascular complication } \\
\text { in the first eye (months) }\end{array}$ & $\begin{array}{c}\mathrm{N} \\
\text { Mean } \pm \mathrm{SD} \\
\text { Min ; Max }\end{array}$ & $\begin{array}{r}540 \\
23.1 \pm \\
2.2 ; 2\end{array}$ & & $\begin{array}{c}536 \\
22.8 \pm 29.6 \\
2.0 ; 323.7\end{array}$ & $\begin{array}{c}1076 \\
22.9 \pm 29.3 \\
2.0 ; 323.7\end{array}$ \\
\hline$<12$ months & $\mathrm{n}(\%)$ & $264(48$ & & $262(48.9 \%)$ & $526(48.9 \%)$ \\
\hline$[12 ; 36]$ months & $\mathrm{n}(\%)$ & $175(32$ & & $181(33.8 \%)$ & $356(33.1 \%)$ \\
\hline$>36$ months & $\mathrm{n}(\%)$ & $101(18$ & & $93(17.4 \%)$ & $194(18.0 \%)$ \\
\hline $\begin{array}{l}\text { OPHTHALMOLOGIC EXAMINATION: STUDIE } \\
\text { EYE }\end{array}$ & & & & & \\
\hline Optimal acuity with correction far & $\mathrm{N}$ & 544 & & 540 & 1084 \\
\hline$[0 / 10 ; 2 / 10[$ & $\mathrm{n}(\%)$ & $5(0.9$ & & $0(0.0 \%)$ & $5(0.5 \%)$ \\
\hline$[2 / 10 ; 5 / 10[$ & $\mathrm{n}(\%)$ & $41(7$. & & $38(7.0 \%)$ & $79(7.3 \%)$ \\
\hline$\geq 5 / 10$ & $\mathrm{n}(\%)$ & $498(91$ & & $502(93.0 \%)$ & $1000(92.3 \%)$ \\
\hline $\begin{array}{l}\text { Optimal acuity with correction near } \\
\text { (Parinaud scale - French patients) }\end{array}$ & $\mathrm{N}$ & 460 & & 438 & 898 \\
\hline $\mathrm{P} 1$ to $\mathrm{P} 3$ & $\mathrm{n}(\%)$ & $435(94$ & & $421(96.1 \%)$ & $856(95.3 \%)$ \\
\hline $\mathrm{P} 4$ to $\mathrm{P} 9$ & $\mathrm{n}(\%)$ & $24(5$. & & $17(3.9 \%)$ & $41(4.6 \%)$ \\
\hline $\mathrm{P} 10$ to $\mathrm{P} 20$ & $\mathrm{n}(\%)$ & $1(0.2$ & & $0(0.0 \%)$ & $1(0.1 \%)$ \\
\hline
\end{tabular}




\begin{tabular}{|c|c|c|c|c|}
\hline $\begin{array}{l}\text { Name of Company: } \\
\text { I.R.I.S. } \\
6 \text { place des Pléiades } \\
92415 \text { Courbevoie - France }\end{array}$ & \multicolumn{2}{|c|}{$\begin{array}{l}\text { Individual Study Table } \\
\text { Referring to Part } \\
\text { of the Dossier }\end{array}$} & \multicolumn{2}{|c|}{ (For National Authority Use only) } \\
\hline $\begin{array}{l}\text { Name of Finished Product: } \\
\text { VASTAREL } ₫ 35 \text { mg - }\end{array}$ & \multicolumn{2}{|l|}{ Volume: } & & \\
\hline $\begin{array}{l}\text { Name of Active Ingredient: } \\
\text { Trimetazidine } M R 35 \mathrm{mg} \\
\end{array}$ & \multicolumn{2}{|l|}{ Page: } & & \\
\hline \multicolumn{5}{|c|}{$\begin{array}{l}\text { STUDY POPULATION AND OUTCOME (CONT'D) } \\
\text { Risks factors at inclusion in the FAS }\end{array}$} \\
\hline & & $\begin{array}{l}\text { TMZ MR } 35 \mathrm{mg} \\
\quad(N=546)\end{array}$ & $\begin{array}{l}\text { Placebo } \\
(N=540)\end{array}$ & $\begin{array}{c}\text { All FAS } \\
(N=1086)\end{array}$ \\
\hline $\begin{array}{l}\text { At least one risk factor } \\
\text { ("smoker" and/or "frequent exposure to the sun" } \\
\text { and/or "at least one cardiovascular risk factor") }\end{array}$ & $\mathrm{n}(\%)$ & $428(78.4 \%)$ & $418(77.4 \%)$ & $846(77.9 \%)$ \\
\hline Smoker & $\mathrm{n}(\%)$ & $70(12.8 \%)$ & $52(9.6 \%)$ & $122(11.2 \%)$ \\
\hline Frequent exposure to the sun & $n(\%)$ & $122(22.3 \%)$ & $126(23.3 \%)$ & $248(22.8 \%)$ \\
\hline At least one cardiovascular risk factor & $\mathrm{n}(\%)$ & $318(58.2 \%)$ & $319(59.1 \%)$ & $637(58.7 \%)$ \\
\hline Diabetes & $\mathrm{n}(\%)$ & $47(8.6 \%)$ & $43(8.0 \%)$ & $90(8.3 \%)$ \\
\hline Hypertension & n $(\%)$ & $283(51.8 \%)$ & $270(50.0 \%)$ & $553(50.9 \%)$ \\
\hline Angina pectoris & n $(\%)$ & $58(10.6 \%)$ & $56(10.4 \%)$ & $114(10.5 \%)$ \\
\hline Myocardial infarction & $\mathrm{n}(\%)$ & $29(5.3 \%)$ & $29(5.4 \%)$ & $58(5.3 \%)$ \\
\hline Cerebrovascular accident & $\mathrm{n}(\%)$ & $22(4.0 \%)$ & $19(3.5 \%)$ & $41(3.8 \%)$ \\
\hline
\end{tabular}

Retinal lesions in the studied eye on inclusion angiography in the FAS

\begin{tabular}{|c|c|c|c|c|}
\hline & & TMZ MR $35 \mathrm{mg}$ & Placebo & All FAS \\
\hline Area covered by serous drusen in their main location & $\mathrm{N}$ & 546 & 539 & 1085 \\
\hline Serous drusen absent & $\mathrm{n}(\%)$ & $35(6.4 \%)$ & $33(6.1 \%)$ & $68(6.3 \%)$ \\
\hline Less than $10 \%$ & $\mathrm{n}(\%)$ & $118(21.6 \%)$ & $96(17.8 \%)$ & $214(19.7 \%)$ \\
\hline Between 10 and $25 \%$ & $\mathrm{n}(\%)$ & $146(26.7 \%)$ & $170(31.5 \%)$ & $316(29.1 \%)$ \\
\hline Between 25 and $50 \%$ & $\mathrm{n}(\%)$ & $146(26.7 \%)$ & $137(25.4 \%)$ & $283(26.1 \%)$ \\
\hline More than $50 \%$ & $\mathrm{n}(\%)$ & $101(18.5 \%)$ & $103(19.1 \%)$ & $204(18.8 \%)$ \\
\hline Highest grade of drusen within the external circle & $\mathrm{N}$ & 544 & 540 & 1084 \\
\hline Moderate dimensions & n $(\%)$ & $46(8.5 \%)$ & $50(9.3 \%)$ & $96(8.9 \%)$ \\
\hline Large dimensions & $\mathrm{n}(\%)$ & $463(85.1 \%)$ & $457(84.6 \%)$ & $920(84.9 \%)$ \\
\hline Grade of drusen most frequent inside external circle & $\mathrm{N}$ & 544 & 540 & 1084 \\
\hline Moderate dimensions & $\mathrm{n}(\%)$ & $170(31.3 \%)$ & $179(33.1 \%)$ & $349(32.2 \%)$ \\
\hline Large dimensions with blurred margins & $\mathrm{n}(\%)$ & $339(62.3 \%)$ & $328(60.7 \%)$ & $667(61.5 \%)$ \\
\hline \multirow[t]{3}{*}{ Mean number of drusen in the eye as a whole } & $\mathrm{N}$ & 535 & 532 & 1067 \\
\hline & Mean $\pm \mathrm{SD}$ & $5.94 \pm 3.94$ & $6.07 \pm 3.93$ & $6.01 \pm 3.93$ \\
\hline & Min ; Max & $0.0 ; 22.8$ & $0.0 ; 19.4$ & $0.0 ; 22.8$ \\
\hline Mean size of drusen in the eye as a whole & $\mathrm{N}$ & 500 & 499 & 999 \\
\hline \multirow[t]{2}{*}{ Eyes without drusen excluded } & Mean \pm SD & $113.16 \pm 56.81$ & $113.01 \pm 56.19$ & $113.09 \pm 56.47$ \\
\hline & Min ; Max & $14.0 ; 251.0$ & $7.0 ; 251.0$ & $7.0 ; 251.0$ \\
\hline Maximum size of drusen in the eye as a whole & $\mathrm{N}$ & 535 & 532 & 1067 \\
\hline$>250$ microns & $\mathrm{n}(\%)$ & $243(45.4 \%)$ & $242(45.5 \%)$ & $485(45.5 \%)$ \\
\hline \multirow[t]{3}{*}{ Mean score of density of the serous drusen } & $\mathrm{N}$ & 535 & 532 & 1067 \\
\hline & Mean \pm SD & $1.935 \pm 1.169$ & $1.950 \pm 1.158$ & $1.942 \pm 1.163$ \\
\hline & Min ; Max & $0.00 ; 5.00$ & $0.00 ; 5.00$ & $0.00 ; 5.00$ \\
\hline Hyperpigmentation & $\mathrm{N}$ & 539 & 535 & 1074 \\
\hline Area greater than 63 microns & $\mathrm{n}(\%)$ & $286(53.1 \%)$ & $293(54.8 \%)$ & $579(53.9 \%)$ \\
\hline Hypopigmentation & $\mathrm{N}$ & 537 & 528 & 1065 \\
\hline Area greater than 63 microns & $\mathrm{n}(\%)$ & $237(44.1 \%)$ & $229(43.4 \%)$ & $466(43.8 \%)$ \\
\hline Hyperpigmentation AND Hypopigmentation & $\mathrm{N}$ & 534 & 527 & 1061 \\
\hline Yes & $\mathrm{n}(\%)$ & $226(42.3 \%)$ & $221(41.9 \%)$ & $447(42.1 \%)$ \\
\hline Hyperpigmentation OR Hypopigmentation & $\mathrm{N}$ & 542 & 536 & 1078 \\
\hline Yes & $\mathrm{n}(\%)$ & $302(55.7 \%)$ & $305(56.9 \%)$ & $607(56.3 \%)$ \\
\hline Main hypo/hyperpigmentation sites & $\mathrm{N}$ & 302 & 305 & 607 \\
\hline In the intermediate field & $\mathrm{n}(\%)$ & $255(84.4 \%)$ & $253(83.0 \%)$ & $508(83.7 \%)$ \\
\hline In the central field & $\mathrm{n}(\%)$ & $38(12.6 \%)$ & $42(13.8 \%)$ & $80(13.2 \%)$ \\
\hline TYPE OF LESIONS ON THE STUDIED EYE & $\mathrm{N}$ & 546 & 540 & 1086 \\
\hline$\geq 5$ isolated serous drusen & $\mathrm{n}(\%)$ & $241(44.1 \%)$ & $232(43.0 \%)$ & $473(43.6 \%)$ \\
\hline$\geq 5$ serous drusen with other drusen or PE lesions & $\mathrm{n}(\%)$ & $270(49.5 \%)$ & $275(50.9 \%)$ & $545(50.2 \%)$ \\
\hline Isolated lesions of the PE & $\mathrm{n}(\%)$ & $35(6.4 \%)$ & $33(6.1 \%)$ & $68(6.3 \%)$ \\
\hline
\end{tabular}




\begin{tabular}{|l|l|l|}
\hline $\begin{array}{l}\text { Name of Company: } \\
\text { I.R.I.S. } \\
\text { 6 place des Pléiades } \\
\text { 92415 Courbevoie - France }\end{array}$ & $\begin{array}{l}\text { Individual Study Table } \\
\text { Referring to Part } \\
\text { of the Dossier }\end{array}$ & (For National Authority Use only) \\
\hline $\begin{array}{l}\text { Name of Finished Product: } \\
\text { VASTAREL® } 35 \mathrm{mg}-\end{array}$ & Volume: & \\
\hline $\begin{array}{l}\text { Name of Active Ingredient: } \\
\text { Trimetazidine MR 35mg }\end{array}$ & Page: & \\
\hline STDY POPULA & & \\
\hline
\end{tabular}

\section{STUDY POPULATION AND OUTCOME (CONT'D)}

\section{Comparability of both treatment groups}

No clinically relevant between-group difference was observed:

- $\quad$ for demographic data and main baseline characteristics, in particular for risk factors and retinal lesions in the studied eye, in the Included Set, FAS, PPS 1 Year and PPS 3 Years.

- for the mean treatment duration in the Included Set (trimetazidine MR $35 \mathrm{mg}: 36 \pm 18$ months; placebo: $34 \pm 18$ months), FAS (trimetazidine MR $35 \mathrm{mg}$ : $38 \pm 16$ months; placebo: $37 \pm 16$ months), PPS 1 Year (trimetazidine MR $35 \mathrm{mg}$ : $42 \pm 14$ months; placebo: $40 \pm 14$ months) and PPS 3 Years (trimetazidine MR $35 \mathrm{mg}$ : $50 \pm 9$ months; placebo: $49 \pm 9$ months).

The treatment compliance was similar in both groups in these four analysis sets. More than $90 \%$ of the patients were compliant (compliance between 70\% and 130\%) in the Included Set (trimetazidine MR $35 \mathrm{mg}: 95.4 \%$ of the patients; placebo: $94.0 \%$ ) and in the FAS (trimetazidine MR $35 \mathrm{mg}$ : $97.8 \%$ of the patients; placebo: $96.3 \%$ ).

The two groups were considered comparable for baseline characteristics and study participation.

\section{EFFICACY RESULTS}

Primary assessment criterion

Incidence of choroidal neovascularisation in the FAS - Comparison between groups

\begin{tabular}{|c|c|c|c|}
\hline & & $\begin{array}{l}\text { TMZ MR } 35 \mathrm{mg} \\
\quad(N=546)\end{array}$ & $\begin{array}{c}\text { Placebo } \\
(N=540)\end{array}$ \\
\hline Exposed patients & $\mathrm{N}$ & 546 & 540 \\
\hline Events & N (\%) & $181(33.2 \%)$ & $177(32.8 \%)$ \\
\hline Exposed patient-years & $\mathrm{N}$ & 1666.7 & 1590.1 \\
\hline Incidence per 100 patient-years & $\mathrm{N}$ & 10.86 & 11.13 \\
\hline Cox's prop. Hazard model & $\begin{array}{l}\text { E (SE) (1) } \\
95 \% \text { CI (2) } \\
\text { p-value (3) }\end{array}$ & \multicolumn{2}{|c|}{$\begin{array}{c}0.971(0.103) \\
{[0.789 ; 1.195]} \\
p=0.781\end{array}$} \\
\hline Logrank test & p-value & \multicolumn{2}{|c|}{$\mathrm{p}=0.781$} \\
\hline $\begin{array}{l}\text { Cox's prop. Hazard model adjusted } \\
\text { on age classes }(\leq 70 \mathrm{y} />70 \mathrm{y})\end{array}$ & $\begin{array}{l}\text { E (SE) (1) } \\
95 \% \text { CI (2) } \\
\text { p-value (3) }\end{array}$ & \multicolumn{2}{|c|}{$\begin{array}{c}0.970(0.103) \\
{[0.789 ; 1.194]} \\
p=0.775\end{array}$} \\
\hline $\begin{array}{l}\text { Logrank test stratified by age classes } \\
(\geq 70 \text { years } />70 \text { years })\end{array}$ & p-value & \multicolumn{2}{|c|}{$\mathrm{p}=0.782$} \\
\hline
\end{tabular}

(1) Estimate (standard error) of the hazard ratio between groups : TMZ MR $35 \mathrm{mg} /$ Placebo

(2) $95 \%$ confidence interval of the hazard ratio estimate

(3) p-value of the likelihood ratio test

No between-group difference in the time to occurrence of choroidal neovascularisation was evidenced, whatever the model and the test used, in t he FAS (Table above) and PPS 1 Year (without adjustment: Cox's model: $p=0.526$ and Logrank test: $p=0.525$; with adjustment on age classes: Cox's model: $p=0.521$ and Logrank test: $\mathrm{p}=0.521$ ). Similar results were obtained for visible neovascularisation and occult neovascularisation in the FAS and PPS 1 Year.

\section{Secondary assessment criterion: atrophy above 1/3 of the papillary diameter}

Occurrence of atrophy above one third of the papillary diameter was observed less often in the trimetazidine MR $35 \mathrm{mg}$-treated patients than in the placebo group in the FAS (trimetazidine MR $35 \mathrm{mg}: 14.7 \%$ of the patients; placebo: 17.5\%) and the PPS 3 Years (trimetazidine MR $35 \mathrm{mg}: 17.8 \%$; placebo: 21.5\%), but the between-group differences were not statistically significant (FAS: $p=0.210$; PPS 3 Years: $p=0.297$ ).

Analysis of the time to occurre nce of atrophy in the FAS by a survival analysis evidenced a between group difference close to the significance what ever the model and the test used (Table below) in favour of an incidence of atrophy during the whole study period lower in the trimetazidine MR $35 \mathrm{mg}$ group than in the placebo group with a hazard ratio between groups of 0.756 . 


\begin{tabular}{|l|l|l|}
\hline $\begin{array}{l}\text { Name of Company: } \\
\text { I.R.I.S. } \\
\text { 6 place des Pléiades } \\
\text { 92415 Courbevoie - France }\end{array}$ & $\begin{array}{l}\text { Individual Study Table } \\
\text { Referring to Part } \\
\text { of the Dossier }\end{array}$ & (For National Authority Use only) \\
\hline $\begin{array}{l}\text { Name of Finished Product: } \\
\text { VASTAREL® } 35 \mathrm{mg}-\end{array}$ & Volume: & \\
\hline $\begin{array}{l}\text { Name of Active Ingredient: } \\
\text { Trimetazidine MR 35mg }\end{array}$ & Page: & \\
\hline
\end{tabular}

EFFICACY RESULTS (CONT'D)

Incidence of atrophy above $1 / 3$ of the papillary diameter in the FAS - Comparison between groups

\begin{tabular}{|c|c|c|c|}
\hline & & $\begin{array}{l}\text { TMZ MR } 35 \mathrm{mg} \\
\quad(N=546)\end{array}$ & $\begin{array}{c}\text { Placebo } \\
(N=540)\end{array}$ \\
\hline Exposed patients & $\mathrm{N}$ & 530 & 530 \\
\hline Events & N (\%) & $78(14.7 \%)$ & $93(17.5 \%)$ \\
\hline Exposed patient-years & $\mathrm{N}$ & 1527.6 & 1442.8 \\
\hline Incidence per 100 patient-years & $\mathrm{N}$ & 5.11 & 6.45 \\
\hline Cox's prop. Hazard model & $\mathrm{E}(\mathrm{SE})(1)$ & \multicolumn{2}{|c|}{$0.756(0.116)$} \\
\hline & $95 \%$ CI (2) & \multicolumn{2}{|c|}{$[0.559 ; 1.022]$} \\
\hline & p-value (3) & \multicolumn{2}{|c|}{0.069} \\
\hline Logrank test & p-value & \multicolumn{2}{|c|}{0.068} \\
\hline Cox's prop. Hazard model adjusted on & $\mathrm{E}(\mathrm{SE})(1)$ & \\
\hline age classes $(\leq 70 \mathrm{y} />70 \mathrm{y})$ & $95 \%$ CI (2) & \multicolumn{2}{|c|}{$[0.559 ; 1.022]$} \\
\hline & p-value (3) & \multicolumn{2}{|c|}{0.069} \\
\hline $\begin{array}{l}\text { Logrank test stratified by age classes } \\
(\geq 70 \text { years } />70 \text { years })\end{array}$ & $\mathrm{p}$-value & \multicolumn{2}{|c|}{0.069} \\
\hline
\end{tabular}

Similar results in favour of an effect of trimetazidine MR $35 \mathrm{mg}$ on atrophy were showed in the FAS for the age class " $\leq 75$ years", the male patients, the subgroup of patients with isolated PE lesions at baseline, the subgroup of patients whose duration of neovascularisation in the first eye was between 12 and 36 months at baseline, and for the subgroups of patients with risk factors of atrophy (Table below).

Incidence of atrophy in the FAS subgroups of patients with risk factors of atrophy

\begin{tabular}{|c|c|c|c|}
\hline & $\begin{array}{c}\text { TMZ MR } 35 \mathrm{mg} \\
(N=546)\end{array}$ & $\begin{array}{c}\text { Placebo } \\
(N=540)\end{array}$ & $p$-value \\
\hline $\begin{array}{l}\text { Hypopigmentation }>63 \mu \text { at baseline } \\
\text { \% of occurrence } \\
\text { Incidence per } 100 \text { patient-years }\end{array}$ & $\begin{array}{l}231 \\
24.2 \% \\
9.73 \\
0.636 \Gamma 0\end{array}$ & $\begin{array}{c}223 \\
34.1 \% \\
14.86 \\
0.8981\end{array}$ & $\begin{array}{l}p=0.020 \\
p=0.010\end{array}$ \\
\hline 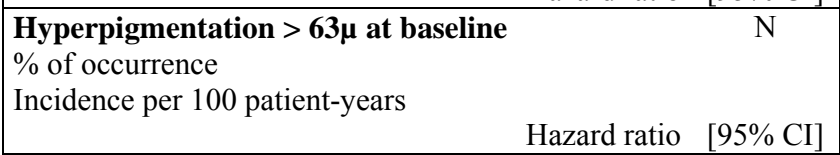 & $\begin{array}{l}277 \\
23.5 \% \\
9.18 \\
0.719[0\end{array}$ & $\begin{array}{l}286 \\
30.1 \% \\
12.56 \\
0.993]\end{array}$ & $\begin{array}{l}\mathrm{p}=0.077 \\
\mathbf{p}=\mathbf{0 . 0 4 4}\end{array}$ \\
\hline 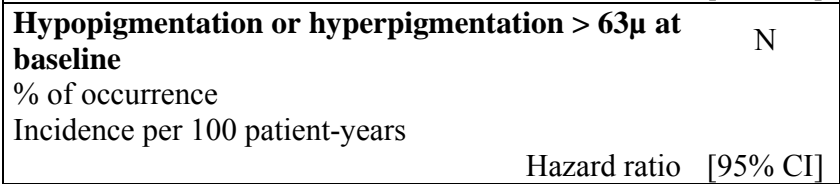 & $\begin{array}{l}293 \\
22.9 \% \\
8.96 \\
0.732[0\end{array}$ & $\begin{array}{l}298 \\
28.9 \% \\
11.96 \\
1.008]\end{array}$ & $\begin{array}{l}\mathrm{p}=0.096 \\
\mathrm{p}=0.055\end{array}$ \\
\hline 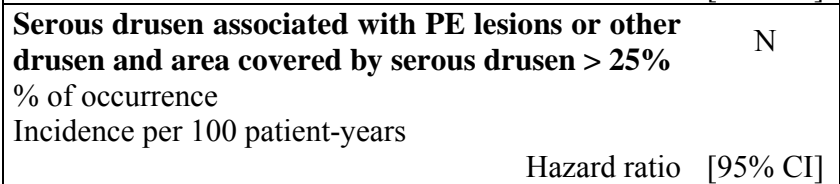 & $\begin{array}{l}137 \\
20.4 \% \\
8.23 \\
0.598[0\end{array}$ & $\begin{array}{l}130 \\
30.8 \% \\
13.71 \\
0.970]\end{array}$ & $\begin{array}{l}\mathrm{p}=0.053 \\
\mathbf{p}=\mathbf{0 . 0 3 5}\end{array}$ \\
\hline $\begin{array}{l}\text { Hypopigmentation }>63 \mu \text { at baseline and area } \\
\text { covered by serous drusen }>25 \% \\
\% \text { of occurrence } \\
\begin{array}{l}\text { Incidence per } 100 \text { patient-years } \\
\end{array} \quad \text { Hazard ratio }[95 \% \mathrm{CI}]\end{array}$ & $\begin{array}{l}101 \\
20.8 \% \\
8.52 \\
0.450[0\end{array}$ & $\begin{array}{c}88 \\
39.8 \% \\
18.91 \\
0.776]\end{array}$ & $\begin{array}{l}p=0.004 \\
p=0.003\end{array}$ \\
\hline 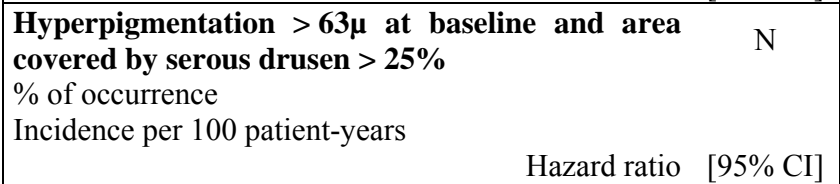 & $\begin{array}{c}129 \\
21.7 \% \\
8.71 \\
0.633[0\end{array}$ & $\begin{array}{c}126 \\
31.7 \% \\
14.06 \\
1.029]\end{array}$ & $\begin{array}{l}\mathrm{p}=0.070 \\
\mathrm{p}=0.063\end{array}$ \\
\hline
\end{tabular}




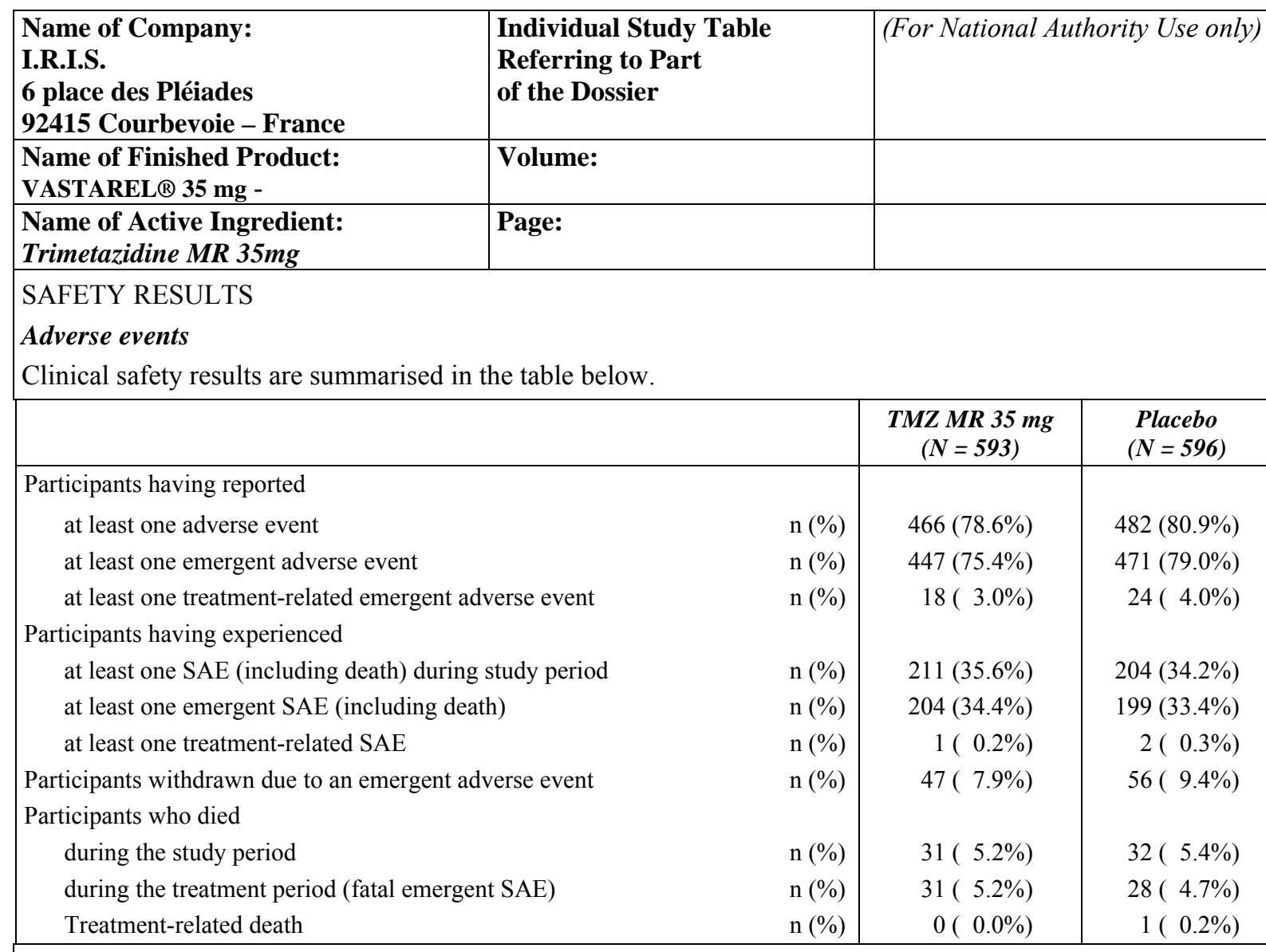

The most frequently system organ class affected by emergent adverse e vents was "Eye dis orders" (trimetazidine MR $35 \mathrm{mg}: 24.6 \%$, placebo: 23.2\%). They were mainly composed of adverse events related either to the $t$ reated disease and its com plications or with ocular diseases that were frequent in the target population (cataract: trimetazidine MR $35 \mathrm{mg}: 4.7 \%$, placebo: 3.0\%). Analysis of cases of cataract and cataract extraction showed that the appearance of cataract, requiring or not its extraction, as well as cataract extractions in patients with cataract before inclusion, were as frequent in the trimetazidine MR $35 \mathrm{mg}$ group as in the placebo group.

The most common treatm ent-related emergent adverse events were gastrointestinal disorders. They were observed in $1.3 \%$ of the trimetazidine MR $35 \mathrm{mg}$-treated patients ( 8 patients having reported 8 adverse events: 4 cases of dyspepsia, 2 cases of gastrointestinal disorder, 1 case of gastrointestinal pain and 1 case of oesophagitis, which required an hospitalisation) and $2.0 \%$ of the patients in the placebo group (12 patients having reported 13 adverse events: 4 cases of gastrointestinal disorder, 2 cases of abdominal pain upper, 2 cases of gastric disorder, 2 cases of nausea, 2 cases of diarrhoea and 1 case of dyspepsia).

Serious adverse events were mainly surgical pr ocedures (7.4\% in each group), cardiac disorders (trimetazidine MR $3 \mathrm{mg}$ : 5.6\%, placebo: 6.4\%) a nd malignant diseases (trimetazidine MR $35 \mathrm{mg}$ : $5.6 \%$, placebo: $5.4 \%$ ) and the first two ca uses of death, cardiac disorders (trimetazidine MR $35 \mathrm{mg}: 1.3 \%$, placebo: $1.5 \%$ ) and malignant diseases (trimetazidine MR $35 \mathrm{mg}: 1.3 \%$, placebo: $1.2 \%$ ).

Only 3 serious adverse events were related to study medication by investigators: 1 case of oesophagitis, which required an hospitalisation in the trimetazidine MR $35 \mathrm{mg}$ group, and in the placebo group, 1 case of epistaxis, who was hospitalised, and 1 case of unexplained death.

After the occurrence of cardiovascular accidents or malignant diseases, the most common cause of treatment withdrawals for adverse events was gastrointestinal disorders (5 trimetazidine MR 35 mg-treated patients: $0.8 \%$, and 12 patients under placebo: $2.0 \%$ ).

Parkinson's disease occurred in 2 patients under trimetazidine MR $35 \mathrm{mg}(0.3 \%)$ and 8 patients in the placebo group $(1.3 \%)$. None of these events was considered as treatment- related by investigator.

No relevant difference between both groups was observed for frequency, nature, intensity, causality, outcome and seriousness of adverse events, except for arterial hypertension and cardiac disorders that were less frequent in the trimetazidine MR $35 \mathrm{mg}$ group than in the placebo group. 


\begin{tabular}{|l|l|l|}
\hline $\begin{array}{l}\text { Name of Company: } \\
\text { I.R.I.S. } \\
\text { 6 place des Pléiades } \\
\text { 92415 Courbevoie - France }\end{array}$ & $\begin{array}{l}\text { Individual Study Table } \\
\text { Referring to Part } \\
\text { of the Dossier }\end{array}$ & (For National Authority Use only) \\
\hline $\begin{array}{l}\text { Name of Finished Product: } \\
\text { VASTAREL } 35 \mathrm{mg} \text { - }\end{array}$ & Volume: & \\
\hline $\begin{array}{l}\text { Name of Active Ingredient: } \\
\text { Trimetazidine MR 35mg }\end{array}$ & Page: & \\
\hline
\end{tabular}

\section{SAFETY RESULTS (CONT'D)}

\section{Other safety evaluations}

Evolution of visual acuity with correction far or $\mathrm{n}$ ear in the studied eye and in the first eye was $\mathrm{n}$ ot clinically different between both groups. The mean intra-ocular pressure remained stable between baseline and last follow-up in both groups.

\section{CONCLUSION}

Under the conditions of this study in which the effects of trimetazidine MR $35 \mathrm{mg}$ on the progression of the AMD lesions were e valuated under double-blind versus placebo in 1192 patients presenting with AMD, characterised by neovascularisation lesions in one eye and serous drusen or lesions of the pigment epithelium in the contralateral eye, an e ffect of trimetazidine MR $35 \mathrm{mg}$ was demonstrated on the occurrence of atrophy above one third of the papillary diameter. This effect was particularly marked for patients having risk factors of atrophy (hypopigmentation, hyperpigmentation, area covered by serous drusen greater than $25 \%$ at baseline).

No significant between group difference was showed for the time to occurrence of choroidal neovascularisation or for the evolution of serous drusen and pigment lesions.

The excellent acceptability of trim etazidine MR $35 \mathrm{mg}$ in elderly was c onfirmed in this long term study. No relevant difference between both groups was observed for frequency, nature, intensity and causality of the reported adverse events, except for arterial hypertension and cardiac disorders that were less frequent under trimetazidine MR $35 \mathrm{mg}$ than in the placebo group. 